\title{
Laboratory cohabitation challenge model for shrimp hepatopancreatic microsporidiosis (HPM) caused by Enterocytozoon hepatopenaei (EHP)
}

Paul Vinu Salachan ${ }^{1,2}$, Pattana Jaroenlak ${ }^{2,3}$, Siripong Thitamadee ${ }^{2,4}$, Ornchuma Itsathitphaisarn ${ }^{2,3}$ and Kallaya Sritunyalucksana ${ }^{1^{*}}$

\begin{abstract}
Background: Enterocytozoon hepatopenaei (EHP) causes hepatopancreatic microsporidiosis (HPM) in shrimp. It is probably endemic in Australasia and was first characterized and named from the giant or black tiger shrimp Penaeus monodon from Thailand in 2009. Later, it was also found to infect exotic Penaeus vannamei imported for cultivation in Asia. HPM is not normally associated with shrimp mortality, but information from shrimp farmers indicates that it is associated with significant growth retardation that is not clearly noticeable until 2-3 months of cultivation. In order to study modes of HPM transmission and to test possible control measures, a laboratory challenge model was needed that would mimic the mode of infection in shrimp ponds.

Results: We describe successful transmission in a cohabitation model with natural E. hepatopenaei (EHP)-infected shrimp in closed, perforated plastic containers placed in aquaria together with free-swimming, uninfected shrimp. After a period of 14 days all the free-swimming shrimp tested positive by PCR (approximately $60 \%$ with heavy infections evident by 1-step PCR positive test results) and gave positive histological and in situ hybridization results for E. hepatopenaei (EHP) in the hepatopancreas.

Conclusions: A laboratory cohabitation model for studying E. hepatopenaei (EHP) has been developed and used to confirm that E. hepatopenaei (EHP) can be directly transmitted horizontally among shrimp via water. The model will facilitate studies on methods to prevent the E. hepatopenaei (EHP) transmission.
\end{abstract}

Keywords: Enterocytozoon hepatopenaei, Shrimp microsporidian, Cohabitation assay, Penaeus vannamei

\section{Background}

Two species of microsporidia have been reported so far as pathogenic to cultivated Penaeus monodon and $P$. vannamei in Thailand. These are Agmasoma penaei [1] and Enterocytozoon hepatopenaei (EHP) [2, 3]. In contrast to E. hepatopenaei (EHP) that does not cause any obvious gross signs of infection, A. penaei infections are characterized by a milky white appearance in the usually translucent musculature of the shrimp abdominal segments, sometimes referred to as "cotton shrimp disease"

\footnotetext{
* Correspondence: kallaya@biotec.or.th

${ }^{1}$ Shrimp-pathogen interaction (SPI) laboratory, National Center for Genetic Engineering and Biotechnology (BIOTEC), National Science and Technology Development Agency (NSTDA), Yothi office, Bangkok 10400, Thailand
} Full list of author information is available at the end of the article in English [4] or "white back disease" in Thai [1, 5, 6]. Microsporidian infections have been recorded in eight species of penaeid shrimp worldwide. [1, 7-16], but only two of them are currently known to infect cultivated shrimp in Thailand and its neighboring countries.

$A$. penaei cannot be transmitted horizontally among shrimp in rearing ponds by either spores or cannibalism $[1,5]$. Since some fish species in Thailand gave PCR positive test results for A. penaei in Thailand $[17,18]$ a successful control strategy was devised that consisted of excluding fish (suspected to be intermediate hosts) from shrimp hatcheries and farms. Because of this practice, the prevalence of cotton shrimp disease (A. penaei infections) in cultivated shrimp in Thailand is very low. 
E. hepatopenaei (EHP) was first described and characterized in 2009 from hepatopancreatic tissue of cultivated black tiger shrimp $P$. monodon in Thailand. However, it had first been reported as a previously uncharacterized microsporidian in juvenile shrimp in 2001 [19] during studies attempting to determine the cause of retarded growth in cultivated $P$. monodon. At that time, results for detection of E. hepatopenaei (EHP) by the presence of spores using light microscopy and confirmation by in situ hybridization did not correlate statistically with the occurrence of retarded growth $E$. hepatopenaei (EHP) morphologically resembles previously reported, unidentified microsporidians from hepatopancreatic tissue of P. monodon in Malaysia [20] and $P$. japonicus in Australia [21], suggesting that E. hepatopenaei (EHP) may be endemic in Australasia and have the capability of infecting multiple species of shrimp. Thus, after introduction and wide-spread cultivation of exotic whiteleg shrimp ( $P$. vannamei) in Asia, outbreaks of HPM caused by E. hepatopenaei (EHP) in cultivation ponds were also reported [3, 22]. This was despite the fact that post-larvae used to stock some of the ponds were originated from specific pathogen free (SPF) broodstock free from E. hepatopenaei (EHP). In pond reared juvenile shrimp, E. hepatopenaei (EHP) infects only tubule epithelial cells of the central region of the hepatopancreas and does not extend into the embryonic cell region (E-cells) [2, 22]. It can sometimes also be seen in cells of the midgut epithelium near its junction with the hepatopancreas.

With respect to disease control in shrimp cultivation ponds, the most important difference between E. hepatopenaei (EHP) and A. penaei is the fact that E. hepatopenaei (EHP) can be horizontally transmitted among shrimp in rearing ponds by cannibalism [3] while $A$. penaei cannot [1]. This makes control in rearing ponds more difficult, and it raised the question as to whether transmission among shrimp in rearing ponds might occur also via E. hepatopenaei (EHP) spores released into the water in shrimp feces. We reasoned that if transmission via spores in water did occur, then cohabitation of E. hepatopenaei (EHP)-infected shrimp with uninfected shrimp would be successful and could be used as a challenge model for testing preventative measures against HPM in the laboratory. Here we describe a successful challenge model for transmission of $E$. hepatopenaei (EHP) in the laboratory by cohabitation of infected shrimp with uninfected shrimp.

\section{Methods}

\section{Collection of infected shrimp and naïve shrimp}

Naïve juvenile $P$. vannamei were acquired together with rearing water from a shrimp nucleus breeding center, while juvenile $P$. vannamei infected with $E$. hepatopenaei
(EHP) were collected together with rearing water from cultivation ponds in and around Bangkok, Thailand. All were transported to the laboratory in plastic containers with proper aeration. They were acclimated at Centex Shrimp in $100 \mathrm{~L}$ tanks containing artificial seawater (Marinium Reef Sea Salt, Mariscience Intl. Co. Ltd, Buenos Aires). From each shrimp lot, 10 samples were arbitrarily selected to test by nested PCR [3] for the presence of $E$. hepatopenaei (EHP) in hepatopancreatic tissue (sufficient to detect its presence at $26 \%$ in the target population with $95 \%$ confidence) [23] to confirm infection in the case of infected shrimp and to confirm absence in the case of naïve shrimp. Since the infected shrimp and naïve shrimp were raised at different salinities (10 ppt and $25 \mathrm{ppt}$, respectively), salinity for all shrimp was adjusted during acclimatization in artificial seawater to $20 \mathrm{ppt}$ by increasing or decreasing the salinity at $2 \mathrm{ppt} / \mathrm{h}$.

\section{Cohabitation assays}

All cohabitation tests were carried out at 20 ppt. Two aquaria containing $150 \mathrm{~L}$ artificial seawater each were set up with 10 infected (10-15 g) juvenile shrimp and 10 naive post larvae $35\left(\mathrm{PL}_{35}\right)(2-4 \mathrm{~g})$ per aquarium. The naive and infected shrimp were separated by having one or the other placed in closed plastic baskets to prevent contact between the two groups (Fig. 1). The shrimp were fed with commercial feed pellets twice a day until the end of the experiment. Three naïve shrimp from each tank were sampled at 7 days and 14 days post cohabitation. Each shrimp was dissected to reveal the hepatopancreas, a small portion of which was put in lysis buffer for DNA extraction. The entire remainder of the whole shrimp was fixed with Davidson's fixative and processed for histopathological analysis by light microscopy following standard methods [24]. Two negative control groups were setup similar to the above

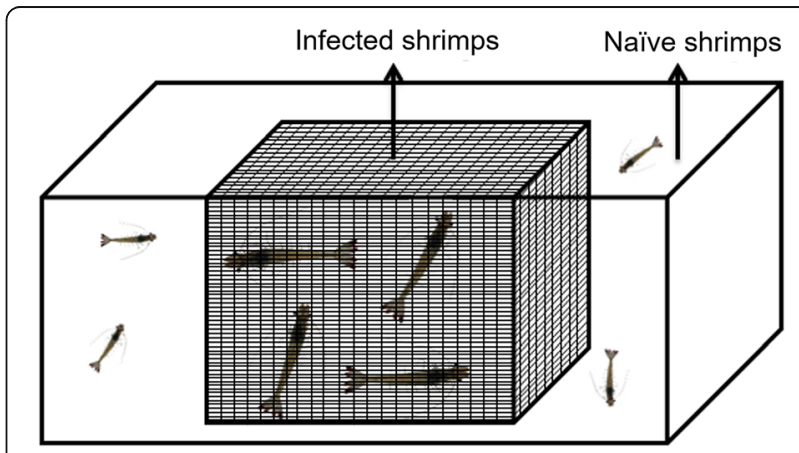

Fig. 1 Schematic drawing (not to scale) of the setup for the cohabitation challenge experiment. In the diagram, naïve shrimp are outside the basket cage and infected shrimp inside. However, the process was also reversed with the same test outcome 
mentioned groups, with 10 naïve shrimp inside the basket cages and 10 naïve shrimp outside.

\section{DNA extraction and PCR detection of E. hepatopenaei (EHP)}

Total DNA was extracted according to the traditional phenol-chloroform method [25]. Hepatopancreatic tissue was homogenized prior to DNA extraction in lysis buffer $(50 \mathrm{mM}$ Tris- $\mathrm{HCl}, \mathrm{pH}$ 9.0, $100 \mathrm{mM}$ EDTA, pH 8.0, $50 \mathrm{mM} \mathrm{NaCl}, 2 \%$ SDS and $10 \mu \mathrm{g} / \mathrm{ml}$ proteinase K). E. hepatopenaei (EHP) was detected using a previously reported nested PCR protocol targeting its SSU rRNA gene [3] yielding amplicons of 779 and 176 bp (Table 1).

\section{Preparation of a DIG-labelled DNA probe for E. hepatopenaei (EHP)}

A DNA probe for in situ detection of E. hepatopenaei in shrimp tissue sections was prepared by PCR using primers ENF411 and ENR176 targeting the SSU rRNA gene (Table 1) in a PCR reaction using a DIGlabelling mix (Roche, Germany) that contained digoxigenin-11-dUTP (DIG-11-dUTP) to substitute for a portion of the dTTP in the dNTP mix. The PCR reaction mix contained $1 \mathrm{X}$ PCR buffer, $1.5 \mathrm{mM}$ $\mathrm{MgCl}_{2}, 0.2 \mu \mathrm{M}$ primers, 1X PCR DIG labelling mix and 1.25 unit Taq polymerase (Invitrogen). The PCR protocol consisted of initial denaturation at $95{ }^{\circ} \mathrm{C}$ for 5 min followed by 35 cycles of denaturation at $95{ }^{\circ} \mathrm{C}$ for 30s, annealing at $58{ }^{\circ} \mathrm{C}$ for 30 s and extension at $72{ }^{\circ} \mathrm{C}$ for $45 \mathrm{~s}$. After a final extension at $72{ }^{\circ} \mathrm{C}$ for $7 \mathrm{~min}$, the reaction was cooled down to $16{ }^{\circ} \mathrm{C}$. The DIG-labelled probe was then run on a $1.2 \%$ agarose gel and the probe band was cut for gel extraction using a NucleoSpin Gel and PCR clean-up kit (Macherey-Nagel, Germany) according to the manufacturer's instructions. The concentration of the probe was measured using a Qubit fluorometer (Invitrogen, USA).
In situ nucleic acid hybridization using the DIG-labelled probe

Paraffin embedded tissue sections were de-paraffinized in xylene and rehydrated before being treated with $5 \mu \mathrm{g} /$ $\mathrm{ml}$ proteinase $\mathrm{K}$ (Invitrogen, USA) in $1 \mathrm{X}$ TNE buffer for $10 \mathrm{~min}$ at $37{ }^{\circ} \mathrm{C}$. The sections were then incubated with $150 \mu$ l pre-hybridization buffer [4X SSC containing 50\% (v/v) deionized formamide] at $37{ }^{\circ} \mathrm{C}$ for $30 \mathrm{~min}$ after which the sections were covered with the DIG-labelled probe (200 ng/slide) in hybridization buffer [containing $50 \%$ deionized formamide, $5 \%$ dextran sulfate, $1 \mathrm{X}$ Denhardt's solution (Sigma), 4X SSC, $250 \mu \mathrm{g} / \mathrm{ml}$ salmon sperm DNA (Invitrogen)]. A cover glass was added followed by incubation at $42{ }^{\circ} \mathrm{C}$ for at least $16 \mathrm{~h}$. This was followed by high stringency washes and equilibration in buffer I $(100 \mathrm{mM}$ Tris- $\mathrm{HCl}$ and $150 \mathrm{mM} \mathrm{NaCl}$, $\mathrm{pH}$ 7.5), followed by incubation in buffer II [Buffer I containing 0.5\% Blocking reagent (Roche, Germany)] for $30 \mathrm{~min}$ at RT. After the incubation, a solution containing alkaline phosphatase conjugated anti-digoxigenin (1:500) was added for $1 \mathrm{~h}$. The unbound antibody was washed off twice using $1 \mathrm{X}$ buffer I before the sections were equilibrated in buffer III $(100 \mathrm{mM}$ Tris- $\mathrm{HCl}$, $100 \mathrm{mM} \mathrm{NaCl}$ and $50 \mathrm{mM} \mathrm{MgCl}_{2}, \mathrm{pH}$ 9.5). Signal was developed by addition of NBT-BCIP substrate (Roche, Germany) and colour development was followed by microscopy before stopping, counterstaining with Bismarck brown Y (Sigma, USA) and dehydrating for preparation of permanent slides.

\section{Results}

\section{Preliminary PCR screening}

All samples of 10 shrimp from all batches of naïve shrimp tested gave negative results by nested PCR analysis for E. hepatopenaei (EHP). At the same time, all of the samples of purported E. hepatopenaei (EHP)-infected shrimp gave positive results by the same test, showing either a single nested PCR amplicon of $176 \mathrm{bp}$ (relatively light infections) or two amplicons (severe

Table 1 Primer sequences used for PCR amplification and E. hepatopenaei (EHP) DIG probe preparation

\begin{tabular}{|c|c|c|c|}
\hline Primer name & Sequence $\left(5^{\prime}-3^{\prime}\right)$ & Amplicon (bp) & Reference \\
\hline $\begin{array}{l}\text { SSU-PCR } \\
1^{\text {st }} \text { PCR }\end{array}$ & & & Tangprasittipap et al. 2013 \\
\hline $\begin{array}{l}\text { ENF779 } \\
\text { ENR779 }\end{array}$ & $\begin{array}{l}\text { CAGCAGGCGCGAAAATTGTCCA } \\
\text { A AGAGATATTGTATTGCGCTTGCT }\end{array}$ & 779 & \\
\hline \multicolumn{4}{|l|}{ Nested PCR } \\
\hline $\begin{array}{l}\text { ENF176 } \\
\text { ENR176 }\end{array}$ & $\begin{array}{l}\text { CAACGCGGGAAAACTTACCA } \\
\text { ACCTGTTATTGCCTTCTCCCTCC }\end{array}$ & 176 & \\
\hline EHP DIG probe & & & This paper \\
\hline ENF411 & AGGTGGTGTTAAAAGCCATTGAG & 235 & \\
\hline ENR176 & ACCTGTTATTGCCTTCTCCCTCC & & \\
\hline
\end{tabular}


infections), one of $779 \mathrm{bp}$ for the first-step PCR and one of $176 \mathrm{bp}$ for the second, nested PCR step.

\section{Cohabitation bioassay}

During the cohabitation experiments, no mortality was expected and none occurred, since HPM is not usually associated with mortality. For the 6 control shrimp sampled (3 each from each of two aquaria) none gave positive nested PCR assay results for E. hepatopenaei (EHP). In addition, none of the 6 specimens from day 14 gave positive in situ hybridization results for E. hepatopenaei (EHP). By contrast, all 6 shrimp samples taken from the E. hepatopenaei (EHP) cohabitation aquaria at day 14 were positive for E. hepatopenaei (EHP) by the nested PCR assay, 4 at the first PCR step (indicating severe infections) and 2 at the nested step only (indicating light infections) (Fig. 2).

\section{Histopathology by H \& E staining and in situ hybridization assays}

H\&E stained sections of HP tissue from the PCR positive cohabitated shrimp specimens showed varying levels of infectivity. Some samples showed extensive histological signs corresponding to E. hepatopenaei (EHP) developmental stages such as plasmodia and spores (Fig. 3), albeit under oil immersion, whereas some samples gave no histological signs of infection, contradicting the PCR results in section 3.2. However, the DNA probe specific for the SSU rRNA gene of $E$. hepatopenaei (EHP) gave positive hybridization results revealing that many of the HP tubule epithelial cells were infected (Fig. 3). This confirmed the E. hepatopenaei (EHP) infections indicated by the PCR results, even though the samples showed no clear developmental stages such as plasmodia and spores by H\&E staining in the single tissue sections examined for each specimen. Although tedious and time consuming, the in situ hybridization

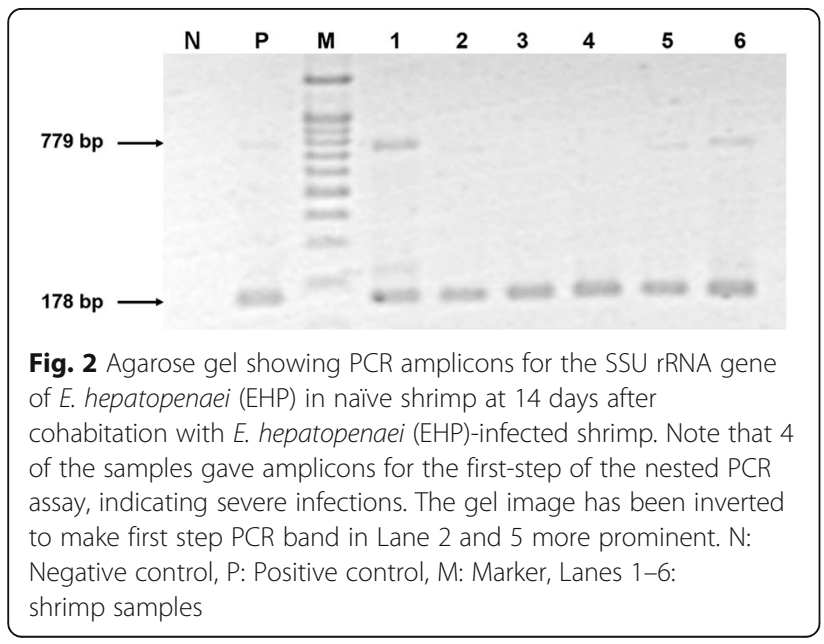

method provided a more reliable and accurate assessment of the severity of infection than did H\&E staining.

\section{Discussion}

The successful cohabitation model described herein overcomes the disadvantage of the previous destructive, oral challenge model using E. hepatopenaei (EHP)-infected hepatopancreatic tissue [3]. It allows for the testing of shrimp broodstock and other potential carriers for infection with $E$. hepatopenaei (EHP) in a nondestructive manner. It also allows for the testing of water or feed treatments for possible efficacy in protecting against E. hepatopenaei (EHP) infection via this natural infection route. Protection might result from treatments to kill spores or to interfere with their process of polar tube extrusion that must occur for the spore contents to enter host cells [26]. The cohabitation model will also be useful for testing potential carriers of $E$. hepatopenaei (EHP) in both directions, i.e., from shrimp to potential carriers and vice versa. At the same time, the previous method of oral challenge using infected HP tissue [3] will still be useful for testing such things as E. hepatopenaei (EHP) inactivation by heating, chilling, freezing, etc.

The main reason we developed this cohabitation method was that spores we had purified by density gradient centrifugation from hepatopancreatic tissue of infected juvenile shrimp following previously published methods [2] failed to induce infections when used by bath exposure, when added to shrimp feed or when administered by reverse gavage (unpublished). The reason for these failures is still unknown. It is possible that the steps in purification by density gradient separation or that refrigeration of the purified spores at $4{ }^{\circ} \mathrm{C}$ inactivated them prior to use in those tests. To address these issues, we attempted to test for viability of the purified, refrigerated spores using previously published methods for vital staining [27] but these failed for reasons including stain uptake by the spore walls, or auto-fluorescence of the spore walls (unpublished). We also tried to induce polar tube extrusion by previously published methods [28], but these tests also failed, possibly indicating that the refrigerated spores were indeed non-viable.

Another possibility is that the spores produced at different host life stages may differ in ability to re-infect the same host. This phenomenon has been previously reported for other microsporidians [29] where spores produced at a later host developmental stage may differ physiologically from those produced at an earlier host stage and that such spores may require some kind of activation step such as drying before they become infectious. It is also possible that spores produced at a later host developmental stage may be destined for an alternative host species. These two possibilities seem unlikely for E. hepatopenaei (EHP) since our cohabitation tests 


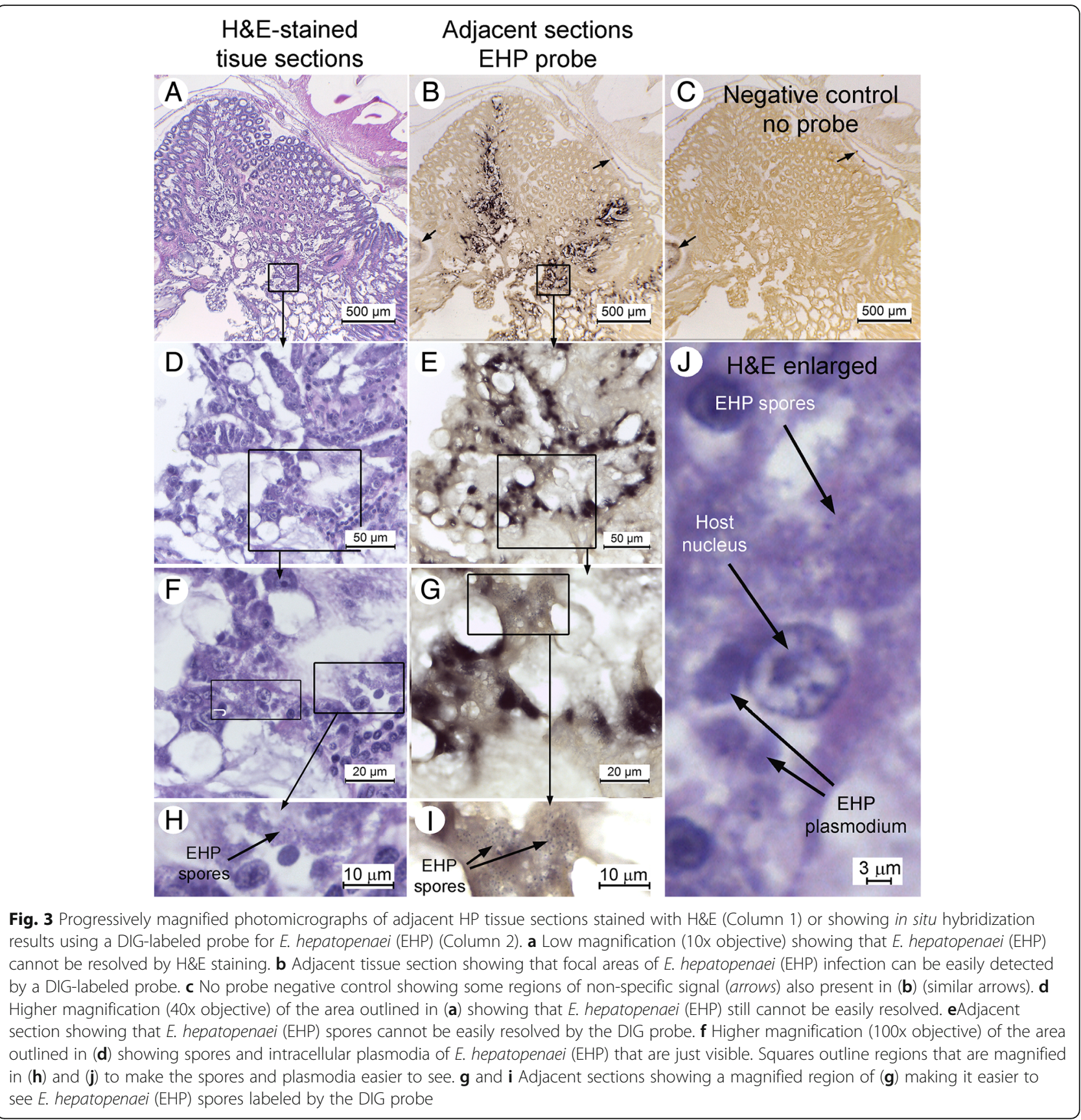

employed infected juvenile shrimp similar in age to those used for spore purification. On the other hand, it is also possible that the juvenile shrimp may produce two different types of spores, one for horizontal transmission and another for transfer to an alternative host. Clearly, much more work is needed on this emerging pathogen to elucidate its host range and life stages.

In addition, during the development of the cohabitation model, our team noticed that assessment of EHP infection purely by the presence of spores by light microscopy can be misleading. Work using an in situ hybridization probe specific for E. hepatopenaei (EHP) with cultivated $P$. vannamei sometimes reveal severe infections (approximately 75\% hepatopancreatic tissue involvement) with few recognizable intracellular stages of plasmodial development and spore production, as assessed by histological analysis of tissue sections [22, 30]. Hence, as demonstrated in this study, in situ hybridization assays with the same tissue section were performed in parallel with the standard H\&E analysis to better estimate the extent of infection. Nonetheless, the histopathological assay is a tedious and time-consuming process. We, 
therefore, recommend instead that PCR based on DNA extracts from homogenates of hepatopancreatic tissue of individual or pooled shrimp samples be used for initial $E$. hepatopenaei (EHP) diagnosis [3, 16, 31]. Moreover, based on current results indicating that the degree of growth retardation from $E$. hepatopenaei (EHP) is positively related to pathogen load, it is probably best to test for E. hepatopenaei (EHP) using quantitative PCR methods ([32], our unpublished work).

\section{Conclusions}

The bioassay for inducing laboratory infection is a primary requirement for studying any newly emerging pathogen and our co-habitation model is straightforward and simple. It can be applied to develop protective treatments for water or feed and to test E. hepatopenaei (EHP) transmission between shrimp and suspected carriers. In the meantime, the problems associated with the use of purified spores may be solved allowing for additional bioassays related to issues such as infectious spore dose.

\section{Abbreviations}

EHP: Enterocytozoon hepatopenaei; NBT-BCIP: HP, Hepatopancreas

\section{Acknowledgments}

The authors would like to thank Prof. T.W. Flegel for assistance in analyzing the experimental data and in preparing this manuscript.

\section{Funding}

This work was supported by funding from the National Research Council of Thailand (to K. Sritunyalucksana).

\section{Availability of data and materials}

The authors confirm that all data underlying the findings are fully available without restriction. All data are included within the manuscript.

\section{Author contributions}

KS and ST conceived and designed the experiments. PS, and PJ performed the experiments. $\mathrm{KS}, \mathrm{Ol}$, and $\mathrm{ST}$ analyzed the data and wrote the paper. All authors read and approved the final manuscript.

\section{Competing interests}

There are no actual or intended patents or products in development or products marketed to declare as being associated with the contents of this manuscript. The information is published to be used freely. Thus, provision of funding entailed no constraints on adherence to all BMC Veterinary Research policies on sharing data and materials.

\section{Consent for publication}

Not applicable.

\section{Ethics approval}

Since the Ethical Principles and Guidelines for the Use of Animals of the National Research Council of Thailand (1999) apply to vertebrates only and there is no official standard for invertebrates, its principles were adapted to shrimp. The guidelines of the Australian, New South Wales state government for the humane harvesting of fish and crustaceans were also followed (http://www.dpi.nsw.gov.au/agriculture/livestock/animal-welfare/general/fish/ shellfish) with respect to details regarding the transport of the shrimp and their laboratory maintenance. With respect to processing the shrimp for histological analysis or for killing at the end of an experiment, the saltwater/ ice slurry method was used as recommended in the Australian guidelines.

\section{Author details}

Shrimp-pathogen interaction (SPI) laboratory, National Center for Genetic Engineering and Biotechnology (BIOTEC), National Science and Technology Development Agency (NSTDA), Yothi office, Bangkok 10400, Thailand. ${ }^{2}$ Center of Excellence for Shrimp Molecular Biology and Biotechnology, Faculty of Science, Mahidol University, Rama VI Rd., Bangkok 10400, Thailand. ${ }^{3}$ Department of Biochemistry, Faculty of Science, Mahidol University, Rama VI Rd., Bangkok 10400, Thailand. ${ }^{4}$ Department of Biotechnology, Faculty of Science, Mahidol University, Rama VI Rd., Bangkok 10400, Thailand.

Received: 26 August 2016 Accepted: 10 December 2016 Published online: 05 January 2017

\section{References}

1. Flegel TW, Boonyaratpalin S, Fegan DF, Guerin M, Sriurairatana S. 1992a. High mortality of black tiger prawns from cotton shrimp disease in Thailand. In: Shariff M, Subasinghe RP, Arthur JR, editors. Diseases in Asian Aquaculture I. Fish Health Section, Asian Fisheries Society. Manila; 1992. p. $181-197$

2. Tourtip S, Wongtripop S, Stentiford GD, Bateman KS, Sriurairatana S, Chavadej J, Sritunyalucksana K, Withyachumnarnkul B. Enterocytozoon hepatopenaei sp. nov. (Microsporida: Enterocytozoonidae), a parasite of the black tiger shrimp Penaeus monodon (Decapoda: Penaeidae):fine structure and phylogenetic relationships. J Invertebr Pathol. 2009;102:21-9.

3. Tangprasittipap A, Srisala J, Chouwdee S, Somboon M, Chuchird N, Limsuwan C, Srisuvan T, Flegel TW, Sritunyalucksana K. The microsporidian Enterocytozoon hepatopenaei is not the cause of white feces syndrome in whiteleg shrimp Penaeus (Litopenaeus) vannamei. BMC Vet Res. 2013;9:139.

4. Lightner DV. A handbook of shrimp pathology and diagnosis procedures for diseases of cultured penaeid shrimp. Baton Rouge: World Aquaculture Society; 1996

5. Flegel TW, Fegan DF, Kongsom S, Vuthikornudomikit S, Sriurairatana S, Boonyaratpalin S, Chantanachookin C, Vickers J, MacDonald O. Occurence, diagnosis and treatment of shrimp diseases in Thailand, In: Fulks W, Main K, editors. Diseases in Cultured Penaeid Shrimp in Asia and the United States. The Oceanic Institute, Honolulu, Hawaii: 1992b. p. 57-112.

6. Prasertsri S, Limsuwan $\mathrm{L}$, Chuchird N. The effects of microsporidian (Thelohania) infection on the growth and histopathological changes in pond-reared Pacific white shrimp (Litopenaeus vannamei). Kasetsart J (Nat Sci). 2009:43:680-8.

7. Sprague V, Cough J. An annotated list of protozoon parasites, hyperparasites and commensals of decapod crustacea. J Protozool. 1971;18: 526-37.

8. Sprague V. Annotated list of species of microsporidia. In: Bulla LA, Cheng TC, editors. Comparative pathobiology, systematics of the microsporidia. New York: Plenum Press; 1977. p. 31-334.

9. Kelly JF. Tissue specificities of Thelohaniaduorara, Agmasoma penaei, and Pleistophora sp., microsporidian parasites of pink shrimp, Penaeus duorarum. J. Invertebr. Pathol. 1979:33:331-9.

10. Clotilde-Ba FL, Toguebaye BS. Ultrastructure and development of Agmasoma penaei (microspora, thelohaniidae) found in Penaeus notialis (crustacea, decapoda, penaeidae) from Senegal. Eur J Protistol. 1994;30: 347-53.

11. Clotilde-Ba FL, Toguebaye BS. Infection of Penaeus monodon (Fabricius, 1798) (crustacea, decapoda, penaeidae) by Agmasoma penaei (microspora thelohaniidae) in Senegal, West Africa. Bull Eur Assn Fish P. 2001;21:157-9.

12. Vidal-Martínez VM, Jiménez-Cueto AM, Simá-Álvarez R. Parasites and symbionts of native and cultured shrimps from Yucatán, Mexico. J Aquatic Anim Health. 2002;14:57-64.

13. Toubiana M, Guelorget $\mathrm{O}$, Bouchereau JL, Lucien-Brun $\mathrm{H}$, Marques A. Microsporidians in penaeid shrimp along the west coast of Madagascar. Dis Aquatic Org. 2004;58:79-82.

14. Laisutisan K, Prasertsri S, Chuchird N, Limsuwan C. Ultrastructure of the microsporidian Thelohania (Agmasoma) penaei in the pacific white shrimp (Litopenaeus vannamei). Kasetsart J (Nat Sci). 2009:33:41-8.

15. Sokolova Y, Pelin A, Hawke J, Corradi N. Morphology and phylogeny of Agmasoma penaei (microsporidia) from the type host, Litopenaeussetiferus, and the type locality, Louisiana. USA Int J Parasitol. 2015;45:1-16.

16. Tang KFJ, Pantoja CR, Redman RM, Han JE, Tran LH, Lightner DV. Development of in situ hybridization and PCR assays for the detection of 
Enterocytozoon hepatopenaei (EHP), a microsporidian parasite infecting penaeid shrimp. J Invertebr Pathol. 2015;130:37-41.

17. Pasharawipas T, Flegel TW, Chaiyaroj S, Mongkolsuk S, Sirisinha S. Comparison of amplified RNA gene sequences from microsporidian parasites (Agmasoma or Thelohania) in Penaeus merguiensis and $P$. monodon. Asian Fisheries Sci. 1994;7:169-78.

18. Pasharawipas T, Flegel TW. A specific DNA probe to identify the intermediate host of a common microsporidian parasite of Penaeus merguiensis and P. monodon. Asian Fish Sci. 1994;7:157-67.

19. Chayaburakul K, Nash G, Pratanpipat P, Sriurairatana S, Withyachumnarnkul B. Multiple pathogens found in growth-retarded black tiger shrimp Penaeus monodon cultivated in Thailand. Dis Aquat Org. 2004;60:89-96.

20. Anderson IG, Shariff M, Nash G. A hepatopancreatic microsporidian parasite in pond-reared tiger shrimp, Penaeus monodon, from Malaysia. J Invertebr Pathol. 1989;53:278-80.

21. Hudson DA, Hudson NB, Pyecroft SB. Mortalities of Penaeusjaponicus prawns associated with microsporidian infection. Aust Vet J. 2001;79:504-5.

22. Thitamadee S, Prachumwat A, Srisala J, Sritunyalucksana K, Flegel TW, Itsathitphaisarn O. Review of current disease threats for cultivated penaeid shrimp in Asia. Aquaculture. 2016;452:69-87.

23. Cameron A. Survey toolbox for aquatic animal diseases: a practical manual and software package. Canberra: Australian Centre for International Agricultural Research; 2002

24. Bell TA, Lightner DV. A handbook of normal penaeid shrimp histology. Baton Rouge: LA:World Aquaculture Society; 1988.

25. Sambrook J, Russell DW. Molecular cloning: a laboratory manual. Cold Spring Harbour; 2001.

26. Bigliardi E, Sacchi L. Cell biology and invasion of the microsporidia. Microbes Infect. 2001;3:373-9.

27. Weber R, Bryan RT, Owen RL, Wilcox CM, Gorelkin L, Visvesvara GS. Improved light-microscopical detection of microsporidian parasite spores instool and duodenal aspirates. New Engl J Med. 1992;326:161-6.

28. Keohane EM, Weiss LM. Characterization and function of the microsporidian polar tube: a review. Folia Parasit. 1998;45:117-27.

29. Vávra J, Lukeš J. Microsporidia and 'the art of living together'. Adv Parasitol. 2013;82:253-319.

30. Flegel TW. Historic emergence, impact and current status of shrimp pathogens in Asia. Invertebr Pathol. 2012;110:166-73.

31. Suebsing R, Prombun P, Srisala J, Kiatpathomchai W. Loop-mediated isothermal amplification combined with colorimetric nanogold for detection of the microsporidian Enterocytozoon hepatopenaei in penaeid shrimp. J Appl Microbiol. 2013;114:1254-63.

32. Liu Z, Zhang QL, Wan XY, Huang J. Development of real-time PCR assay for detection of microsporidian Enterocytozoon hepatopenaei and detection in shrimp samples under different growth rates. Prog Fish Sci. 2016;37:119-26.

\section{Submit your next manuscript to BioMed Central and we will help you at every step:}

- We accept pre-submission inquiries

- Our selector tool helps you to find the most relevant journal

- We provide round the clock customer support

- Convenient online submission

- Thorough peer review

- Inclusion in PubMed and all major indexing services

- Maximum visibility for your research

Submit your manuscript at www.biomedcentral.com/submit

) Biomed Central 